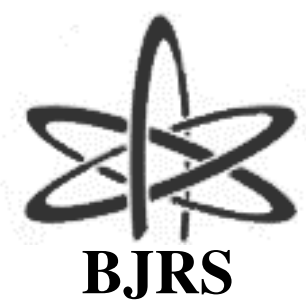

BRAZILIAN JOURNAL

$\mathrm{OF}$

RADIATION SCIENCES

03-1A (2015) 01-10

\title{
Use of an anthropomorphic hand phantom to verify the radiation intensity that is needed to modify the analog and digital radiographic quality
}

\author{
C. K. Bandeira ${ }^{\text {a. }}$ M. P. M. M. Vieira ${ }^{\text {b }}$ J. E. R. Felix ${ }^{\mathrm{c}}$ \\ ${ }^{a}$ Campus Curitiba, Instituto Federal do Paraná , 80230-150, Curitiba-PR, Brasil \\ kretezel@hotmail.com \\ ${ }^{b}$ Campus Curitiba, Instituto Federal do Paraná , 80230-150, Curitiba-PR, Brasil \\ michele.vieira@ifpr.edu.br \\ ${ }^{c}$ CEFORES, Universidade Federal do Triângulo Mineiro, 38025-015, Uberaba-MG, Brasil \\ felix@anomati.net
}

\begin{abstract}
The radiology is a field of medicine that is in constantly expansion and advancing. This can be noticed with the transition from analog to digital radiology systems, it is important that professionals understand image formation in both systems in order to produce radiographies with diagnostic quality. Therefore, the objective of this work is to present the importance of radiological protection by changing values of technical parameters while the quality of radiographic imaging is sustained. An anthropomorphic hand phantom was built in order to obtain radiographies as it is necessary to respect the Brazilian regulations (Portaria 453/98) which forbids the use of radiation in patients for testing. Three analog and eight digital radiographies were obtained using fixed $\mathrm{kVp}$ and varying $\mathrm{mAs}$. Each image was compared to the others acquired in the same location. Digital radiographies have shown that approximately $28 \%$ of change in mAs is necessary to change noise, whereas approximately $33,3 \%$ is necessary in the analog system to change density. The conclusion is that computerized systems need less x-ray intensity to modify image features and moreover can reduce the patient radiation doses. However, more testing must be conducted in different radiologic environments to confirm the results obtained in the present study.
\end{abstract}

Keywords: phantom, radiological protection, quality control

Palavras-chave: phantoms, proteção radiológica, controle de qualidade. 


\section{INTRODUÇÃO}

Nas últimas décadas houve uma crescente expansão das áreas de tecnologia e informática, que também pode ser observada na área da saúde. Esta expansão pode ser observada nos diferentes setores de imagem, sejam eles em locais públicos ou privados, por meio de uma tendência à substituição do sistema de aquisição de imagem analógico para o digital. Devido a esta transição, surgem mudanças no fluxo de trabalho e nas funções dos profissionais da radiologia. Com a modificação na forma de obtenção das imagens, tarefas como limpar e trocar os químicos da processadora automática não são mais necessárias aos técnicos e tecnólogos em radiologia. Outra alteração na rotina dos profissionais é o modo de selecionar parâmetros técnicos de exposição $(\mathrm{kVp}, \mathrm{mA}$ e tempo de exposição), pois os receptores de imagem são distintos e consequentemente o modo como é formada a imagem radiográfica também (BUSHONG, 2010). Entretanto, em ambos os sistemas a determinação dos parâmetros técnicos de exposição é um dos principais responsáveis pela qualidade diagnóstica da imagem radiográfica, dessa forma o objetivo deste trabalho é apresentar a importância da proteção radiológica por meio de alterações no parâmetro técnico mAs, buscando manter a qualidade radiográfica das imagens. Este parâmetro foi escolhido, pois ele está relacionado a demais critérios no que refere-se à avaliação de qualidade radiográfica.

Partindo dessa premissa, observou-se a necessidade da construção de um fantoma para a execução de testes que contribuíssem com a compreensão da influencia do $\mathrm{kVp}$ e mAs na imagem. Além disso, pode auxiliar na conscientização da importância da seleção adequada destes parâmetros, no que tange a aplicação da proteção radiológica e consequente redução de dose para o paciente, durante a transição do sistema analógico para o digital.

A seguir serão apresentados elementos relacionados à formação das imagens radiográficas e suas características nos diferentes sistemas de aquisição, que contribuem para a melhor compreensão dos testes executados e das imagens obtidas nestes dois sistemas.

$\mathrm{Na}$ radiologia analógica, a imagem é formada diretamente no filme radiográfico, colocado no interior de um cassete. Esse filme é composto por cristais de haletos de prata que serão 
sensibilizados por fótons de raios $\mathrm{X}$ e de luz, formando a imagem latente, que torna-se visível após o processo de revelação, podendo este ser manual ou automático (DO VAL, 2006).

A qualidade da imagem radiográfica obtida é analisada com base em quatro características: densidade, contraste, detalhe e distorção. A densidade é o grau de enegrecimento da imagem e está relacionado com a intensidade da radiação que atinge o filme radiográfico, portanto o mAs é o parâmetro técnico que altera diretamente esta característica (DO VAL, 2006).

O contraste de uma radiografia é a diferença entre as densidades de imagens das estruturas, ou seja, é percebido através da escala dos tons de cinzas da radiografia. Ele é influenciado diretamente pela tensão de pico, kVp (DO VAL, 2006).

O detalhe da imagem depende da densidade e do contraste radiográficos, e representa a nitidez que permite visualizar as bordas das estruturas anatômicas da região de interesse. Já a distorção está interligada à forma e à magnificação destas estruturas e é ajustada por parâmetros como distância foco-receptor de imagem, entre outros (DO VAL, 2006).

Em contrapartida, a radiologia digital é divida em computadorizada e digital direta, sendo que a computadorizada é composta basicamente por uma placa de imagem (Image Plate - IP), um receptor de imagem, semelhante ao do analógico, e o leitor. A IP é composta por cristais de fósforo que mantêm os elétrons em armadilhas quando estes absorvem energia ao serem expostos a fótons de raios X. E, enquanto a IP passa pelo leitor, ela é atingida por um feixe laser capaz de liberar os elétrons dessas armadilhas. Nesse processo eles liberam fótons, de frequência próxima ao da luz azul, que são direcionados ao tubo fotomultiplicador e convertidos em sinal elétrico para serem visualizados como imagem na tela do computador. Em sequência, a IP é exposta à luz branca intensa para liberar elétrons que ainda estão nas armadilhas, de modo a deixar a placa pronta para ser utilizada novamente (BONTRAGER, 2010).

Os critérios para avaliar a qualidade radiográfica digital são os mesmos utilizados para imagens analógicas, porém também estão incluídos: o índice de exposição e o ruído. O índice de exposição é representado por um valor que indica a quantidade de radiação recebida pela IP. Ele também pode ser chamado de valor de sensibilidade (S) e dependendo do software utilizado, este valor pode ser direta ou indiretamente proporcional à exposição. Para cada região anatômica há uma faixa de valores de $\mathrm{S}$ que indica se a radiografia não está subexposta ou superexposta, e portanto não perdeu qualidade diagnóstica (BONTRAGER, 2010). 
O ruído é caracterizado por alterações aleatórias que ofuscam a imagem ou reduzem a claridade. Este critério confere a imagem uma aparência granulada que prejudica a visualização de tecidos moles. Ele também está interligado com a intensidade de radiação que atinge o receptor, ajustada pelo mAs, que pode ser considerado como o sinal. Quando o sinal é maior que o ruído, diz-se que a imagem possui uma relação sinal ruído (RSR) baixa, e quando o sinal for menor a imagem possui RSR baixa (BONTRAGER, 2010).

\section{MATERIAIS E MÉTODOS}

Considerando que a portaria 453/98 do Ministério da Saúde proíbe a execução de testes em pacientes, para a obtenção das imagens foi construído um fantoma antropomórfico, que é um objeto que simula a interação da radiação com os tecidos de regiões do corpo humano e tem a forma anatômica da estrutura (BRASIL, 1998).

O fantoma antropomórfico utilizado neste trabalho simula a região anatômica da mão, representando o esqueleto apendicular, constituído basicamente por ossos e partes moles. Este fantoma foi confeccionado com base nos materiais tecido-equivalentes disponíveis no Radiation International Commission on Radiation Units \& Measurements, report 44 (ICRU, 1989).

Os materiais empregados na construção do fantoma foram: acrílico autopolimerizante e parafina, simulando, respectivamente, ossos e partes moles. Inicialmente foram obtidos dois moldes, um da parte anterior e outro da posterior do esqueleto da mão, utilizando-se silicone para a confecção do molde, como é observado na Figura 1.

Figura 1: Molde de silicone da região da mão para confecção de esqueleto da mão

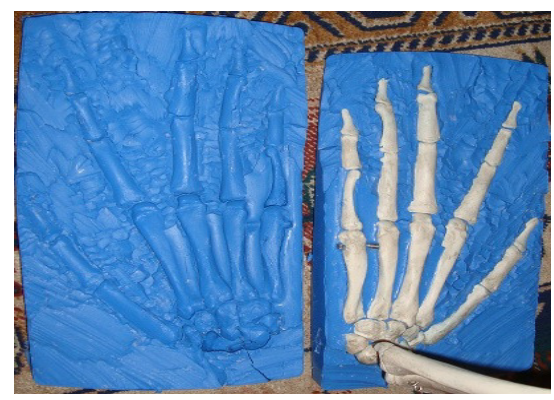

Fonte: Autoria própria 
Em cada molde foi vazado o acrílico autopolimerizante, e em seguida as metades foram unidas e comprimidas para que o acrílico tomasse o formato dos ossos do carpo, metacarpo e falanges. A estrutura em acrílico retirada do molde foi lixada, para remover o excesso de acrílico que se acumulou ao redor das falanges, e assim tomasse a forma do esqueleto da mão, apresentado na Figura 2.

Figura 2: Estrutura em acrílico representando os ossos da mão

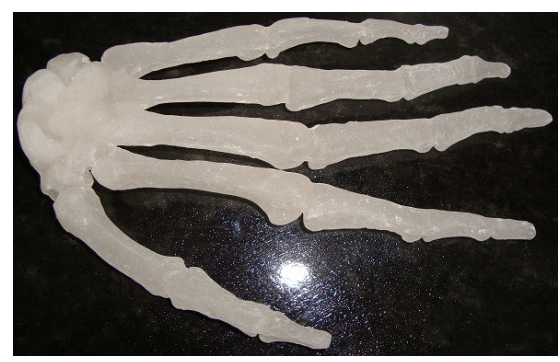

Fonte: Autoria própria

Para simular partes moles, a parafina foi derretida e colocada em um recipiente de modo que o esqueleto de acrílico pudesse ser imerso e retirado do material até formar uma camada de parafina sobre a sua estrutura. $\mathrm{O}$ fantoma construído pode ser observado na Figura 3.

Figura 3: Fantoma antropomórfico da mão construído com acrílico e parafina

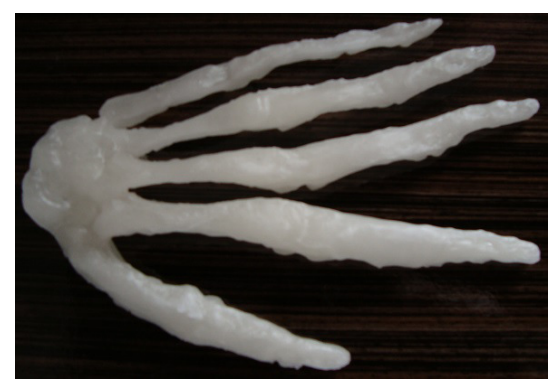

Fonte: Autoria própria

Após o processo de construção do fantoma antropomórfico, foram obtidas radiografias em dois ambientes radiológicos distintos, sendo que um possuía sistema analógico e o outro computadorizado. Em cada local foram determinados valores de $\mathrm{kVp}, \mathrm{mA}$ e tempo de exposição 
conforme as combinações que o equipamento de raios $\mathrm{X}$ permitia selecionar, e que resultassem em imagens com qualidade. Em seguida o valor do $\mathrm{kVp}$ foi mantido constante e somente os valores do mAs foram modificados. A partir dessas alterações é possível verificar qual sistema de aquisição de imagens necessita de menor quantidade de radiação para produzir alterações na qualidade diagnóstica da imagem.

As imagens adquiridas em cada local foram compradas entre si, para que os demais parâmetros que alteram a qualidade da imagem (tipo de equipamento, por exemplo) se mantivessem invariáveis, e assim fossem observadas as mudanças nas características da imagem radiográfica conforme o valor do mAs utilizado.

\section{RESULTADOS E DISCUSSÕES}

O processo de aquisição das imagens resultou em onze radiografias, sendo que três foram obtidas em sistema analógico e oito em sistema computadorizado. As radiografias digitais foram adquiridas com $55 \mathrm{kVp}$, pois este é o valor mínimo recomendado pela empresa responsável pelo sistema. Dentre as radiografias digitais, três, adquiridas com 2,5 mAs, 3,2 mAs e 4,0 mAs, apresentaram valores de sensibilidade respectivamente iguais a 118, 103 e 105, e portanto encontravam-se dentro dos padrões de qualidade recomendados pelo software que está na faixa de 75 a 200. Estas imagens radiográficas estão apresentadas na Figura 4.

Figura 4: Radiografias obtidas em sistema computadorizado com diferentes valores de mAs utilizando o fantoma de mão
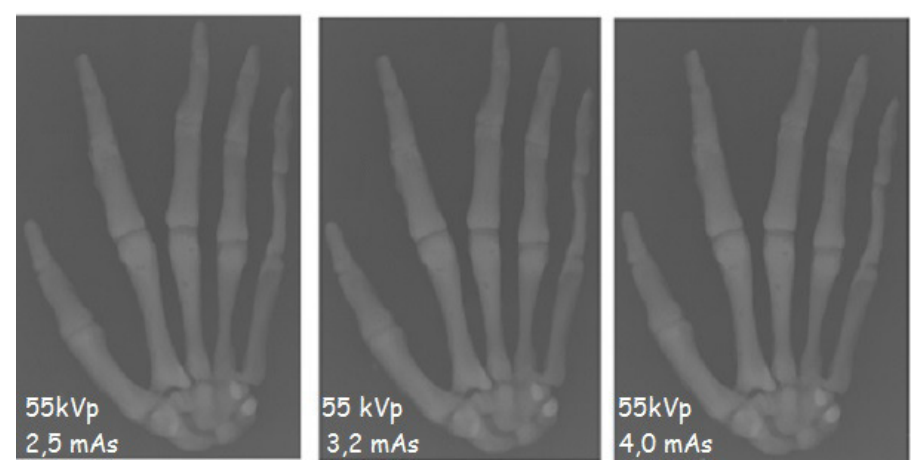

Fonte: Autoria própria 
Como o $\mathrm{kVp}, \mathrm{mA}$, tipo de equipamento, chassi e demais parâmetros que influenciam na qualidade da imagem foram mantidos invariáveis, ao observar a Figura 4 nota-se que entre as radiografias obtidas com 2,5 mAs e 3,2 mAs, houve um aumento de $28 \%$ no valor deste parâmetro que resultou em uma redução do ruído da imagem radiográfica.

Também percebeu-se que aumentos de até $60 \%$ no valor do mAs, a partir do valor de 2,5, não geraram alterações na densidade radiográfica, somente na relação sinal ruído. A utilização de valores acima de $4 \mathrm{mAs}$ resultaram em perda na qualidade diagnóstica e os valores de sensibilidade encontraram-se fora da faixa recomendada pelo fabricante.

A Figura 5 apresenta uma imagem radiográfica obtida com 4,8 mAs, $55 \mathrm{kVp}$ e com valor de sensibilidade (S) igual a 50, ou seja, inferior ao indicado. E, como no local de aquisição da imagem o S é inversamente proporcional à exposição recebida, a radiografia apresentou perda na qualidade radiográfica devido a quantidade de radiação utilizada estar acima da que é necessária.

Figura 5: Radiografia computadorizada com valor de sensibilidade fora da faixa recomendada pelo fabricante, obtida com o fantoma de mão

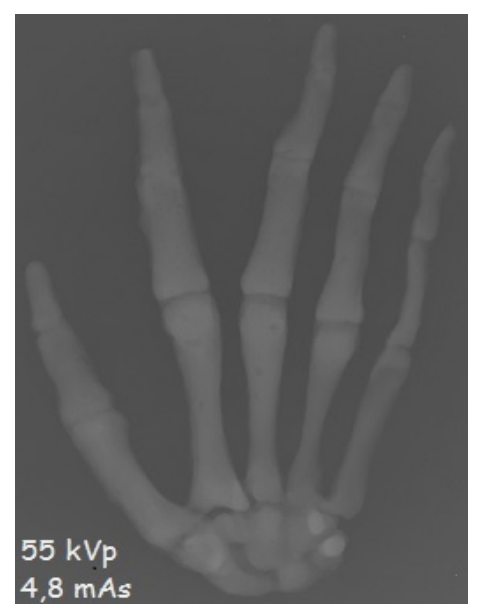

Fonte: Autoria própria

A Figura 6 apresenta as radiografias obtidas no sistema analógico. Para aquisição das imagens foram utilizados $44 \mathrm{kVp}$ e os valores de $2 \mathrm{mAs}, 3 \mathrm{mAs}$ e $4 \mathrm{mAs}$. Estes valores foram determinados conforme as combinações entre corrente elétrica e tempo de exposição que o aparelho de raios X disponibilizava para selecionar. Ao observar a Figura 5 é possível verificar 
que foi necessário um aumento de cerca de 33,3\% no valor de mAs para modificar a densidade radiográfica, e também notou-se que o aumento de 50\% no mAs alterou significativamente a densidade radiográfica, conforme é apresentado pela literatura.

Figura 6: Radiografias analógicas obtidas com $44 \mathrm{kVp}$ e diferentes valores de mAs, utilizando o fantoma de mão. (a) Imagem obtida com 4 mAs, (b) imagem obtida com 3 mAs, (c) imagem obtida com 2 mAs

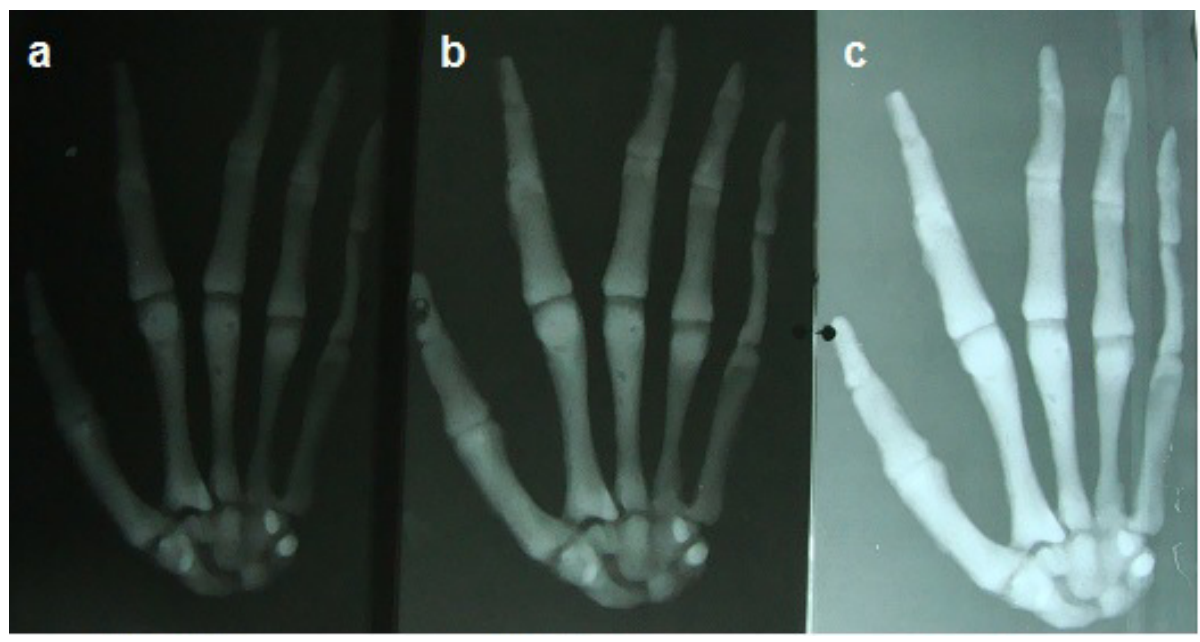

Fonte: Autoria própria

A partir da comparação entre as radiografias obtidas com o fantoma antropomórfico de mão, notou-se que há diferenças entre a porcentagem da intensidade de radiação necessária para alterar as características das imagens radiográficas nos sistemas computadorizado e analógico. A variação no valor do mAs para modificar o ruído da imagem na radiologia computadorizada é inferior a variação para alterar a densidade nas imagens analógicas, portanto, com a transição da radiologia analógica para a computadorizada é possível utilizar uma menor dose de radiação para melhorar a qualidade da imagem radiográfica. 


\section{CONCLUSÕES}

Pode-se concluir que no sistema computadorizado uma larga escala de valores de mAs pode gerar imagens com densidade óptica adequada, porém é importante que os profissionais das técnicas radiológicas conheçam essa faixa para que sempre selecionem os valores de mAs mais baixos que resultam em radiografias dentro dos padrões de qualidade e que consequentemente respeitem os princípios de proteção radiológica. Para tanto podem ser realizados testes com a utilização de fantomas, que tem apresentado grande relevância tanto para o ensino de parâmetros técnicos quanto no controle de qualidade de equipamentos de raios $\mathrm{X}$.

Identificou-se também a necessidade da realização de novos testes com o fantoma antropomórfico de mão, em outros ambientes radiológicos, para avaliar diferenças entre equipamentos de diferentes marcas e modelos com a finalidade de aumentar o número de amostragem para confirmar os resultados encontrados na execução deste trabalho.

Considerando trabalhos futuros espera-se construir novos fantomas de diferentes regiões anatômicas como, por exemplo, a região do abdome que apresenta em sua imagem radiográfica estruturas com densidades radiográficas similares o que, em prática, pode representar uma dificuldade para evidenciar determinadas patologias.

A construção de novos fantomas permitirá a realização de novos testes que contribuam para manutenção dos princípios de proteção radiológica. Isto significa que o técnico/tecnólogo em radiologia terá a possibilidade de compreender como a variação dos parâmetros técnicos pode diminuir a dose de radiação que o paciente recebe, sem perder a qualidade diagnóstica da imagem.

Este artigo foi aprovado pelo RADIO2014 e encontra-se nos anais do mesmo.

\section{AGRADECIMENTO}

Agradecemos ao Instituto Federal do Paraná (IFPR) pelo espaço e apoio a pesquisa; ao CNPq, pelo apoio financeiro dado ao projeto; aos ambientes radiológicos pelo uso dos equipamentos para a realização deste trabalho. 


\section{REFERÊNCIAS}

BONTRAGER, K. L.; LAMPIGNANO, J. P. Tratado de posicionamento radiográfico e anatomia associada. $7^{\text {th }}$ ed., Rio de Janeiro: Elsevier, 2010.

BRASIL. Ministério da Saúde. Secretaria de Vigilância Sanitária. Portaria $n^{\circ} 453$, de $01^{\circ}$ de junho de 1998. Aprova o Regulamento Técnico que estabelece as diretrizes básicas de proteção radiológica em radiodiagnóstico médico e odontológico, dispõe sobre o uso dos raios-x diagnósticos em todo território nacional e dá outras providências. Diário Oficial da União da República Federativa do Brasil, Brasília, 02 de junho de 1998.

BUSHONG, S. C. Ciência radiológica para tecnólogos, $9^{\text {th }}$ ed., Rio de Janeiro: Elsevier, 2010.

DO VAL, F. L. Manual de técnica radiográfica. São Paulo: Manole, 2006.

ICRU - International Commission on Radiation Units and Measurements. Tissue substitutes in Radiation Dosimetry and Measurement. ICRU Report 44, Bethesda: ICRU, 1989. 22p. 